COMMENT

Check for updates

https://doi.org/10.1057/s41599-020-0403-x

\title{
Deglobalization in a hyper-connected world
}

\author{
José Balsa-Barreiro (10 ${ }^{1 凶}$, Aymeric Vié ${ }^{2}$, Alfredo J. Morales ${ }^{1,2} \&$ Manuel Cebrián ${ }^{3}$
}

\begin{abstract}
In the age of hyperconnectivity, we are undergoing an explosive increase in the interdependence of the political, commercial, financial, and social spheres. The recent rise of deglobalization movements across the world highlights the local negative externalities of poorly designed networked structures at the global scale: high social complexity derived from immigration shocks, elevated risk of contagion in financial downturns, as well as increasing inequality and social polarization. While global interdependencies on networks enable opportunities for cultural and economic growth, they also establish channels for unresolved conflicts and design errors to propagate across social systems. We analyze failure propagation on networks as a function of density and centralization of inter-dependencies. We show that the risk of failure in both overly distributed and centralized systems behave similarly when the number of connections exceeds a system-dependent threshold number. The scale of interdependencies matters and must be considered for the design of policies targeted at increasing or decreasing the connectivity of social systems.
\end{abstract}

\footnotetext{
${ }^{1}$ MIT Media Lab, Cambridge, USA. ${ }^{2}$ New England Complex Systems Institute, Cambridge, USA. ${ }^{3}$ Center for Human and Machines, Max Planck Institute for

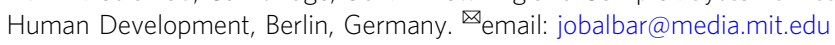




\section{Introduction}

n 1929, Frigyes Karinthy proposed the Theory of Six Degrees of Separation. According to him, two randomly selected individuals are potentially connected by an average sequence of six other individuals (Watts, 2003). A similar and popular myth in New York City says that someone standing in Times Square will probably meet an acquaintance in less than $20 \mathrm{~min}$. The recent introduction of mobile devices, Internet applications, and social media have dramatically increased the interconnectivity of the globe in an unprecedented manner. The distance between individuals has never been lower (Shu and Chuang, 2011; Zhang and Tu, 2009).

Understanding the structure of human interconnections and their impact on economic and social activities are crucial for social sciences (Granovetter, 2005). The establishment of connections and interdependencies may yield benefits and opportunities both for businesses (Hidalgo et al., 2007) and social organizations (Bar-Yam, 2002), among others. For instance, the combination of components provided by multiple agents is the basis for the growth of economic complexity and innovation (Kauffman, 1995). In recent years, our economic system is being increasingly globalized fostering a permanent flow of goods and people across borders. This is manifested in the creation and expansion of free-trade zones such as the European Economic Area (EEA), the North American Free Trade Agreement (NAFTA), and the ASEAN-China Free Trade Area (ACFTA), which reveal the architecture of a unified global market.

As a reaction to the globalized economy, some political movements have confrontationally emerged in recent years. Major episodes such as the Brexit referendum (2016) or the elections of Donald Trump in the United States (2016) and Bolsonaro in Brazil (2018), as well as the outcome of other minor elections and referendums across Europe and the Americas, show that these trends are relevant. For James (2018) these episodes are the start point of a deglobalization process all around the world, which is evidenced by misalignment and confrontation between people and the Establishment (Inglehart and Norris, 2016). Regulations for building borders and protecting the market are being debated after a prolonged period of increasing deregulation. Understanding and managing these issues is a challenge for both scientists and policy-makers.

This confrontation can be explained by the complexity of social systems, which arises from the structural patterns of social interdependencies. How people self-organize and behave has historically become increasingly complex across multiple civilizations (Tainter, 2006). From a scientific perspective, traditional methods are insufficient for thorough modeling of such complexity (Strogatz, 2001). In this regard, the theory of complex systems provides tools for understanding the behavior of social systems by decomposing them into small parts and analyzing the structure of their relationships (Barábasi, 2009). Social relationships and interdependencies account for more of the complexity of social systems than individual properties or functionalities in isolation.

The complexity of systems refers to the diversity and heterogeneity of behaviors at multiple scales, ranging from individuals to communities or societies at large. The addition of interdependencies increases the number of potential relationships among the system parts, enabling the emergence of new types of association and more elaborate behaviors. Interdependencies are the basis for the emergence of collective capabilities that would otherwise be unfeasible. Individuals associate with one another by coupling their behaviors to increase the space of possibilities of the whole system at a larger scale.

However, adding interdependencies has a hidden downside. The more connected a system is, the easier is for errors and unexpected detrimental behaviors to propagate across the system.
Interdependencies create new paths for error propagation and may escalate the risks of malfunctions in both frequency and severity (Newman et al., 2006). Anomalies do not grow or occur linearly. Their magnitude may explode given the existence of critical masses and tipping points during networked propagation processes. Analyzing systemic failure exceeds traditional research methods that simplify reality by analyzing errors in isolation.

Material science and mechanical engineering consider this kind of failure. A mechanical structure becomes more vulnerable to future shocks when multiple loads are continuously applied to them. The structure crashes when the load forces overcome the resistance threshold of any part or material, which becomes more sensitive due to the repeated load forces. A fatigue process that results from the establishment of interdependencies among the material parts after exceeding certain thresholds explains this system failure.

A system with a great number of interdependencies can be extremely vulnerable to malfunctions, even if it does not come from the most important nodes. The chaos theory, which is inherent to complex systems, explains that small variations may entail huge changes in entire systems. Similarly, any potential malfunction can effortlessly cascade across the whole system and affect its functional behavior. Some concrete examples related to these effects are appreciated in very different kinds of systems, both with natural and human inception. Natural events such as forest wildfires or the consequences of earthquakes in some regions eventually manifest catastrophic dimensions and huge regional differences that go beyond the phenomenon itself (BalsaBarreiro and Hermosilla, 2013).

The science of complex systems analyzes the structure and dynamics of different types of systems. This structure (also called topology) determines the hierarchical relationships among nodes. Three common network representations are shown in Fig. 1. In the case of (a) centralized systems, the whole network is connected to a single node that is centrally located. In (b) decentralized systems, the links between nodes are distributed among hubs located at different parts of the network. Finally, (c) in distributed systems, the links between nodes are equally distributed along with the network. Systems such the shown in (a) are very sensitive to the malfunctioning of the central node, which is connected to most of the network and its eventual malfunctioning will spread easily across the whole system. Such malfunctioning can come from its behavior or by propagating the failure of any of its neighbors. Likewise, systems such the shown in (c) whose connections are distributed equally across all nodes, may be very vulnerable to the propagation of failures only if the number of interdependencies exceeds a certain threshold and the system becomes too connected.

After the 2008 debt crisis, cascading phenomena have become a hot research topic. Not surprisingly, a substantial part of the literature in economics and finance studies is focused on understanding systemic risks and the stability within the global markets (May et al., 2008). Many studies combine disciplines such as network science and evolutionary biology to understand how seemingly stable economies become unstable at a certain point (Sugihara, 2010). Haldane and May (2011) observed a sharp transition to instability in economic networks once critical thresholds were exceeded. More recently, Bardoscia et al. (2017a) outlined the crucial role of the structure of networks for estimating systemic risks. These findings are crucial for designing methods to create robust economies and mitigate financial risks.

\section{Discussion}

Systems become fragile when perturbations damage their behaviors. This may happen because nodes are excessively 


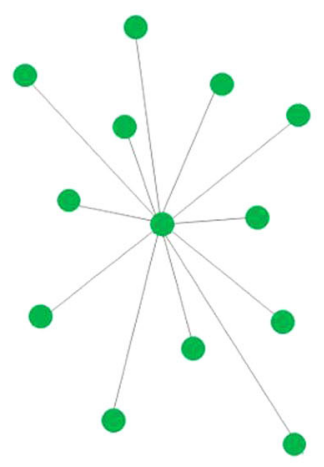

(a)

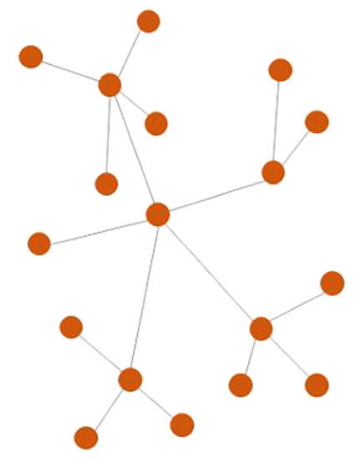

(b)

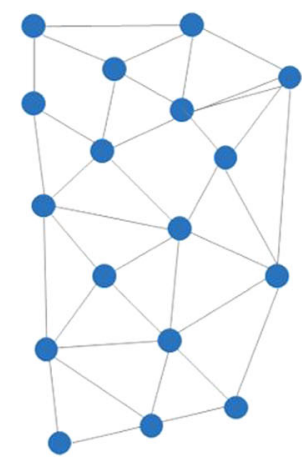

(c)

Fig. 1 Representation of different network topologies. Network with a central, $\mathbf{b}$ hub, and $\mathbf{c}$ distributed structure. These plots are analogous to the centralization model shown in Fig. $2 \mathrm{~b}$ for $\alpha=2, \alpha=1$, and $\alpha=0$, respectively.

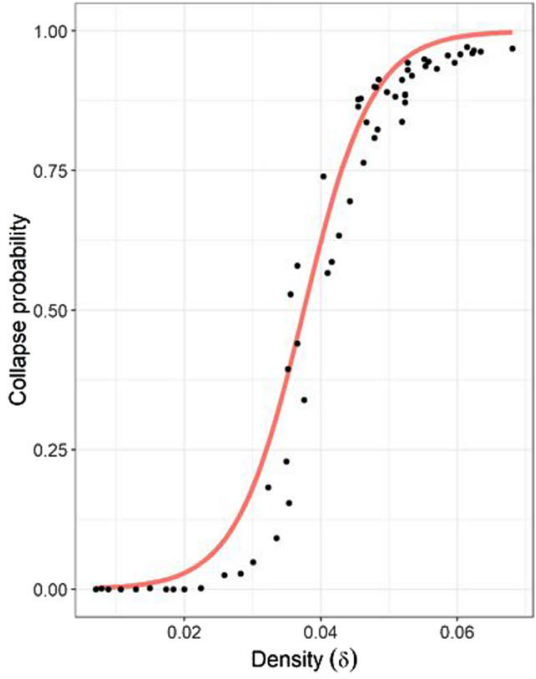

(a)

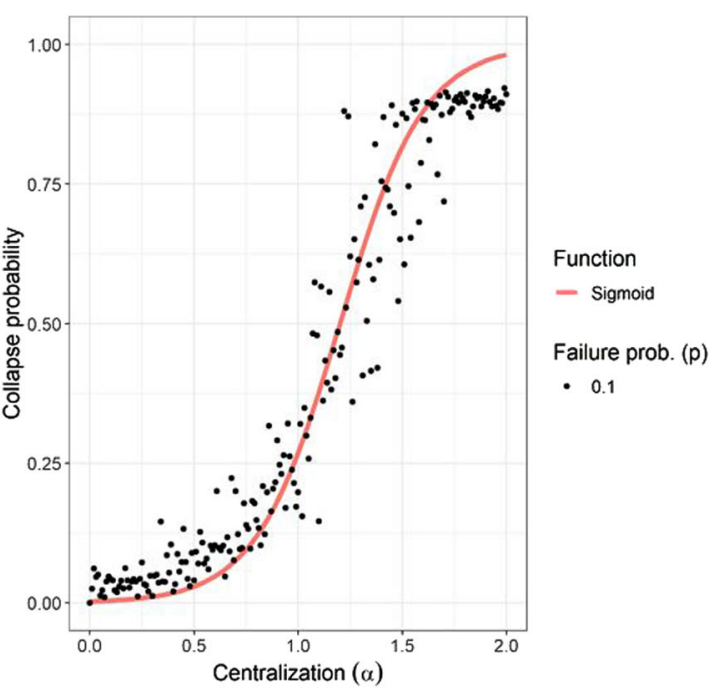

(b)

Fig. 2 Collapse probability as a function of network connectivity. Collapse probability-y-axis-depending on a the level of density of interdependencies and $\mathbf{b}$ the degree of centralization of the network-both shown in $x$-axis. Density indicates the relative number of possible randomly distributed connections. Centralization control for the weight of hubs in the network ranging from $\alpha=0$ (no hubs, also called Erdös-Rényi random network) to $\alpha=2$, which corresponds to a perfect centralized network where all nodes are connected to a central one. In between, a Barábasi scale-free network, which corresponds to $\alpha=1$. A sigmoidal curve fits the simulation data, showing a universal behavior between the two different types of network's topologies.

interconnected or these mostly depend on a much-reduced number of central nodes. Vié and Morales (2019) analyzed the propagation of failures on different topologies of economic networks, where nodes represented agents and edges economic interdependencies. Agents create products as a function of the interdependencies established with the network neighbors. A high number of connections increase the products and economic activities they can engage in. During simulations, agents can fail with a given likelihood (failure probability). Flawed nodes propagate errors to direct neighbors, affecting their abilities to be economically productive. The model is applied to multiple network topologies that differ in two different directions: (a) increasing the number of interdependencies among nodes and (b) reinforcing the centralization of the network. The option (a) is evaluated by increasing the density of random connections among all the nodes of the network such it happens in unregulated free markets (Fig. 1c). The option (b) is evaluated by increasing the number of connections only just in the central nodes (Fig. 1a).
While establishing connections may increase the complexity of the economy, it also increases the risks of cascading failure due to a potential excess of interconnections. We define systemic collapse as the case when the network productivity drops below the reference level of the system working in the absence of network connectivity (i.e., having established any connection where information or goods are exchanged). Figure 2 shows the probability of systemic collapse after 10,000 experiments for different network densities (Fig. 2a) and levels of centralization (Fig. 2b). The probability of collapse is shown in the $y$-axis and the rate of connectivity in the $x$-axis. These plots exhibit a universal sigmoidal behavior where tipping points in the topology critically increases the risk of systemic collapse. The s-curve pattern in charts shows that an excessive amount of interdependencies tends to spread failures throughout the whole system once certain thresholds are exceeded. Bardoscia et al. (2017b) estimated this threshold for some economic production chains. Traditional cascade models show that the size of cascades is scale-free at the critical threshold (Bak and Chen, 1991). 
The collapse of centralized systems has been evident in political governance as it happened in the former republics of the Soviet Union. These countries were centrally planned economies, which were managed by a reduced number of people. However, their over-centralized power tended to amplify the corruption effects from the central state agencies. Additionally, the overload of bureaucracy and the excessive concentration of administration tasks and responsibilities slowed down economic abilities to respond and adapt to the requirements of both the market and people. It constrained economic development and led to a systemic inefficiency of the whole government.

In the case of decentralized systems, it can also happen that some nodes exceed their capacity due to an growing number of interdependencies. It was observed in the recent economic crisis in Europe, where the financial systems of all the member states were highly interconnected. Thus, despite the efforts and mechanisms of the European Union (EU) authorities for avoiding a contagion effect, the opening of new and critical paths for risk transmission was evident. EU authorities had to approve multiple and substantial financial bailouts to Greece since early world financial crisis ( $\$ 146$ billion in 2010, $\$ 172$ billion in 2012, $\$ 86$ billion in 2015) despite the Greek economy accounts for less than $2 \%$ of the EU GDP (with around $\$ 200$ billion in 2017) (CFR, 2019). Even so, the collapse risks could not be fully controlled. In the present, consequences of such collapse have clearly reached beyond the initial economic crisis into the sociopolitical sphere. Strong reactionary movements, mostly nationalists, have accompanied the austerity policies implemented across the region (Balsa-Barreiro, 2012). Within complex systems theory, these deglobalization movements are signaling the need for a reduction of interdependencies among national economies.

\section{Summary}

The complexity of a networked system, ranging from the social to the economic, to the political, is associated with its structural topology. Interdependencies are critical for understanding the trade-offs between efficiency and robustness in such systems. While public debate questions whether the public or private sector should be regulated, reformed, or ultimately empowered, the role of the interdependencies of these sectors with their global counterpart is a crucial dimension in the system behavior yet often overlooked. Whether by over-centralizing or by excessively densifying dependencies, a poor design can lead to the collapse of the whole system.

Received: 9 October 2019; Accepted: 21 January 2020;

Published online: 25 February 2020

\section{References}

Bak P, Chen K (1991) Self-organized criticality. Sci Am 264(1):46-53

Balsa-Barreiro J (2012) La crisis económica y el cambio en el poder geopolítico en Europa. Le Monde Diplomatique. Online publication September 2. https:// www.lemondediplomatique.cl/la-crisis-economica-y-el-cambio-en-el-podergeopolitico-en-europa-por-jose. Accessed 20 Dec 2019

Balsa-Barreiro J, Hermosilla T (2013) Socio-geographic analysis of the causes of the 2006's wildfires in Galicia (Spain). For Syst 22(3):497-509

Barabási AL (2009) Scale-free networks: a decade and beyond. Science 325 (5939):412-413
Bar-Yam Y (2002) Complexity rising: from human beings to human civilization, a complexity profile. In: Encyclopedia of Life Support Systems (EOLSS). United Nations, Oxford, UK

Bardoscia M, Battiston S, Caccioli F, Caldarelli G (2017a) Pathways towards instability in financial networks. Nat Commun 8:14416

Bardoscia M, Livan G, Marsili M (2017b) Statistical mechanics of complex economies. J Stat Mech: Theory Exp 4:043401

Council of Foreign Affairs, CFR (2019) [online] https://www.cfr.org/timeline/ greeces-debt-crisis-timeline. Accessed 20 Dec 2019

Granovetter M (2005) The impact of social structure on economic outcomes. J Econ Perspect 19(1):33-50

Haldane AG, May RM (2011) Systemic risk in banking ecosystems. Nature 469 (7330):351

Hidalgo CA, Klinger B, Barabási AL, Hausmann R (2007) The product space conditions the development of nations. Science 317(5837):482-487

Inglehart R, Norris P (2016) Trump, Brexit, and the rise of populism: economic have-nots and cultural backlash. HKS Faculty Research Working Paper Series RWP16-026

James H (2018) Deglobalization: the rise of disembedded unilateralism. Annu Rev Financ Econ 10:219-237

Kauffman SA (1995) At home in the universe. The search for laws of selforganization and complexity. Oxford University Press, Oxford

May RM, Levin SA, Sugihara G (2008) Complex systems: ecology for bankers. Nature 451:893-895

Newman M, Barabási A, Watts D (2006) The structure and dynamics of networks. Princeton University Press, Princeton

Shu W, Chuang Y (2011) The perceived benefits of six-degree separation social networks. Internet Res 21(1):26-45

Strogatz SH (2001) Exploring complex networks. Nature 410(6825):268

Sugihara G (2010) On early warning signs. Global Reset. SEED Mag January 60-65. https://www.seedmagazine.com/content/article/on_early_warning_signs/. Accessed 20 Nov 2019

Tainter JA (2006) Social complexity and sustainability. Ecol Complex 3(2):91-103 Vié A, Morales A (2019) How connected is too connected? Impact of network connectivity on systemic risk and collapse of complex economic systems. Preprint at arxiv:1912.09814. Accessed 20 Dec 2019

Watts DJ (2003) Six degrees: the science of a connected age. Random House, London

Zhang L, Tu W (2009) Six degrees of separation in online society. Distribution 3 (12): $1-5$

\section{Competing interests}

The authors declare no competing interests.

\section{Additional information}

Correspondence and requests for materials should be addressed to J.B.-B.

Reprints and permission information is available at http://www.nature.com/reprints

Publisher's note Springer Nature remains neutral with regard to jurisdictional claims in published maps and institutional affiliations.

\begin{abstract}
Open Access This article is licensed under a Creative Commons Attribution 4.0 International License, which permits use, sharing, adaptation, distribution and reproduction in any medium or format, as long as you give appropriate credit to the original author(s) and the source, provide a link to the Creative Commons licence, and indicate if changes were made. The images or other third party material in this article are included in the article's Creative Commons licence, unless indicated otherwise in a credit line to the material. If material is not included in the article's Creative Commons licence and your intended use is not permitted by statutory regulation or exceeds the permitted use, you will need to obtain permission directly from the copyright holder. To view a copy of this licence, visit http://creativecommons.org/ licenses/by/4.0/.
\end{abstract}

(c) The Author(s) 2020 